\title{
Combined treatment of exudative age related macular degeneration with photodynamic therapy and intravitreal triamcinolone
}

\author{
José $M^{a}$ Ruiz-Moreno ${ }^{1,2}$ \\ Javier A Montero² \\ 'Department of Ophthalmology, \\ Miguel Hernández University School \\ of Medicine, Alicante, Spain; ${ }^{2}$ Vitreo- \\ Retinal Unit, Alicante Institute of \\ Ophthalmology, Alicante, Spain
}

\begin{abstract}
Choroidal neovascularization (CNV) secondary to age related macular degeneration is among the leading causes of legal blindness in developed countries. Photodynamic therapy (PDT) with verteporfin induces CNV closure causing little damage to healthy tissue, but the need to re-treat may lead to low final visual acuity at an unacceptable cost. The association of intravitreous triamcinolone or antiangiogenic drugs with PDT has been used in order to reduce these limitations of the therapy. The combination of PDT and intravitreous triamcinolone, its complications and outcome at one and two-year follow-up are discussed.
\end{abstract}

Keywords: age related macular degeneration, choroidal neovascularization, photodynamic therapy, steroid, triamcinolone

\section{Introduction}

Photodynamic therapy (PDT) with verteporfin significantly reduces visual acuity (VA) loss in cases with subfoveal choroidal neovascularization (CNV) secondary to exudative age related macular degeneration (AMD) (Anon 1999; Bressler 2001), as well as the patient's perception of scotoma (Schmidt-Erfurth et al 2004). However, several sessions are frequently needed to achieve complete closure of the lesions (3.4 during the first year, 2.2 during the second year and 1.3 during the third year) as was demonstrated by the results of randomized clinical trials (Anon 1999; Bressler 2001; Blumenkranz et al 2002) and the final VA outcome is usually considered not good enough by the patient and the ophthalmologist.

It has been reported that CNV permeabilization and growth associated with exudative AMD make it necessary to perform repeated PDT sessions, reducing its cost-effectiveness (Sharma et al 2001; Meads and Hyde 2004; Brown et al 2005). Repeated PDT sessions may cause retinal damage and result in progressive thinning of the neurosensory retina (Reinke et al 1999; Peyman et al 2000), as well as closure of normal choroidal vessels (Michels and Schmidt-Erfurth 2003).

Combined therapies have been considered necessary to reduce the number of re-treatments and the progressive loss of VA. Intravitreal triamcinolone acetonide (TA) has been associated with PDT in order to join the short-term effect of PDTinduced CNV closure (Meads and Hyde 2004) and the antiangiogenic and antiinflammatory effects of TA (Spaide et al 2003). Intravitreal injection of TA is cheap and relatively safe, and TA appears to have a long half-life in the vitreous cavity (Tano et al 1980).

We have tried to determine the benefits of combining the short-term effect of PDTinduced CNV closure (Miller et al 1995), with the antiangiogenic and anti-inflammatory effects of TA (Tano et al 1980). 


\section{Material and methods}

We analyzed the results of combined PDT and high dose TA in 30 eyes from 30 patients with AMD-associated CNV at the Alicante Institute of Ophthalmology at 12 and 24 month follow-up. The study was performed in accordance to the ethical standards of the 1964 Declaration of Helsinki, and data gathering was performed after obtaining written informed consent and approval of the Ethics Committee.

Patients older than 50 years of age with AMD-associated subfoveal CNVs verified by fluorescein angiography (FA) were included. CNVs occupied more than $50 \%$ of total lesion area; greatest linear dimension of the lesion was less than $5400 \mu \mathrm{m}$ and baseline intraocular pressure (IOP) was under $21 \mathrm{mmHg}$.

Three groups of patients were considered. Group 1 comprised 15 naïve patients; Group 2 comprised 15 patients who had previously received PDT and showed persistent leakage on FA. We also considered 15 patients with AMD-associated subfoveal CNV who had been treated at our clinic with standard PDT as a Control Group. The three groups were not significantly different for age, sex, best corrected visual acuity (BCVA), CNV size, and lesion type at baseline (RuizMoreno et al 2006b).

Conventional PDT as previously described (Anon 1999) was followed by an intravitreal injection of $19.4 \pm 2.1 \mathrm{mg}$ TA in $0.1 \mathrm{ml}$ five days later. This concentration of TA was obtained by allowing the $40 \mathrm{mg} / \mathrm{ml}$ triamcinolone suspension to precipitate within the injecting syringe (Ruiz-Moreno et al 2006a; Ruiz-Moreno et al 2006b; Ruiz-Moreno et al 2007).

CNV leakage or growth demonstrated by FA was treated by additional PDT sessions not sooner than three months later. New TA injections were performed combined with PDT at six months intervals, when necessary.

Main outcome variables were BCVA at baseline and at month 12 and 24 (LogMAR), changes in visual acuity (Snellen lines), number of PDT sessions per patient, and appearance of adverse events.

\section{Results}

Demographics have been previously described (Ruiz-Moreno et al 2006b; Ruiz-Moreno et al 2007). Three patients in Group 2 had been treated by PDT once; six patients twice; four patients three times; one patient four times; and one patient six times (Ruiz-Moreno et al 2006b; Ruiz-Moreno et al 2007).

One patient (case 14) was excluded from Group 1 at month 3 due to migration of triamcinolone into the anterior chamber. One patient (case 2) in Group 2 lived far from the medical center and refused to return for follow-up visits.

Differences between baseline and 12 month BCVA for Groups 1 and 2 were not statistically significant $(p=0.49$ and $p=0.10$ respectively, Student $t$ test for paired data). BCVA in the Control Group at month 12 was significantly worse than in Groups 1 and 2 ( $p=0.004$, ANOVA). The changes in BCVA during the second year compared with baseline were not statistically significant for Groups 1 and 2 ( $p=0.94$ and $p=0.34$ respectively, Student $t$ test for paired data). BCVA in the Control Group was significantly worse $(p=0.04$, Student $t$ test for paired data).

The presence of fluorescein leakage and the need for PDT are shown in Table 1. The difference in the number of PDT sessions needed to stop FA leakage was statistically significant at months 3, 6, 9, and 12 for Groups 1 and 2 compared to the historical Control Group. The average number of PDT sessions for the two-year period was 3.9 for the Control Group, 1.9 for Group 1 and 1.2 for Group 2. The average number of intravitreal TA injections was 1.5 in Group 1 and 1.2 in Group 2. A second injection was needed in nine eyes during the 2 year follow-up.

Fifteen (54\%) of 28 eyes from Groups 1 and 2 had high IOP needing medical therapy during the first year. There were no cases of increased IOP in the Control Group. No new cases of IOP elevation appeared during the second year. Two eyes with high IOP needed a second intravitreal TA injection at month 15 , which did not affect IOP.

IOP rose in five cases one month after the injection, in four cases at month 3 , in four cases at month 6 , in one case at month 7, and in one case at month 9. One single topical drug controlled IOP in seven cases; two drugs were needed in seven cases, and one case underwent $180^{\circ}$ diode laser cycloablation. The number of patients needing therapy to control IOP decreased progressively, and by the end of the second year

Table I Number of PDT sessions performed

\begin{tabular}{lllll}
\hline Month & $\begin{array}{l}\text { Control } \\
\text { group }\end{array}$ & Group I & Group 2 & $\begin{array}{l}\text { Statistical } \\
\text { significance }\end{array}$ \\
\hline 3 & $14 / 15(93 \%)$ & $5 / 14(36 \%)$ & $1 / 15(7 \%)$ & $\mathrm{P}<0.000$ \\
6 & $10 / 15(67 \%)$ & $3 / 14(21 \%)$ & $2 / 15(13 \%)$ & $\mathrm{P}=0.004$ \\
9 & $7 / 15(47 \%)$ & $1 / 14(7 \%)$ & $0 / 14(0 \%)$ & $\mathrm{P}=0.032$ \\
12 & $5 / 15(33 \%)$ & $0 / 14(0 \%)$ & $0 / 14(0 \%)$ & $\mathrm{P}=0.005$ \\
15 & $2 / 14(14 \%)$ & $2 / 14(14 \%)$ & $0 / 14(0 \%)$ & $\mathrm{NS}$ \\
18 & $2 / 14(14 \%)$ & $1 / 14(7 \%)$ & $0 / 14(0 \%)$ & $\mathrm{NS}$ \\
21 & $0 / 13(0 \%)$ & $0 / 13(0 \%)$ & $0 / 13(0 \%)$ & $\mathrm{NS}$ \\
24 & $0 / 13(0 \%)$ & $0 / 13(0 \%)$ & $0 / 13(0 \%)$ & $\mathrm{NS}$ \\
\hline
\end{tabular}

${ }^{\mathrm{a}} \mathrm{Chi}$ square test.

Abbreviation: NS, not statistically significant. 
only 6 of 26 eyes (23\%) still needed topical treatment to control IOP: two patients with two drugs, and four patients with one drug. Systemic drugs were not needed to control IOP.

Crystalline lens opacification (defined by a 2-level increase in lens opacity according to The Lens Opacities Classification System III (Chylack et al 1993) appeared in 12 eyes (55\%) from 22 phakic eyes in groups 1 and 2 completing 24 month follow-up and in none of the eyes from the historical control group. Cataract surgery was performed without complications in these cases.

Floaters were described by patients in the first few days after the injection and disappeared later in all cases. One case in Group 2 (case 13) suffered a central retinal vein occlusion at month 12. TA migrated into the anterior chamber in one case the day after the injection (Ruiz-Moreno et al 2005). There were no cases of endophthalmitis.

\section{Discussion}

PDT is known to increase local production of vascular endothelial growth factor (VEGF), what might be linked with frequent recurrences (Wang et al 2002). Patients treated by PDT alone have been reported to need repeated PDT sessions in $90.8 \%$ of the cases at month-3 and slightly less at month-6, with an average 3.3 sessions in the first year of therapy, and an average loss of 2.2 lines at month 12 (Anon 1999).

The development of new anti-VEGF drugs (Gragoudas et al 2004; Avery et al 2006) and the knowledge on the inhibitory role of steroids in the production of VEGF offer new approaches to the treatment of CNV.

The association of PDT and intravitreal TA to treat subfoveal CNV secondary to AMD has been reported by several groups (Jonas et al 2003; Spaide et al 2003; Augustin and Schmidt-Erfurth 2006b; Ruiz-Moreno et al 2006b).

A number of non-randomized studies have shown that the frequency of PDT sessions is reduced with combined therapy. Combined PDT-TA (4 mg) results in a better outcome than PDT alone, with reduction of the number of PDT sessions to 1.24 over the first year and improved VA outcome by 2.5 lines after 12 months follow-up (Chan et al 2006). The need to retreat was reduced to 3 of 14 eyes, with a favorable visual outcome in most of the treated patients (Nicolo et al 2006). Spaide reported that the association of PDT and $4 \mathrm{mg}$ intravitreal TA significantly improved average visual acuity by 2.5 lines at 12-month follow-up. The rate of re-treatment was 1.24 for naïve eyes and 1.2 for eyes previously treated by PDT alone over the first year (Spaide et al 2003; Spaide et al 2005). Rechtman has reported $21 \%$ of eyes needing PDT re-treatment after combined therapy with PDT and $4 \mathrm{mg}$ TA, with a favorable visual outcome after six to twelve months follow-up (Rechtman et al 2004).

Our results with $19.4 \pm 2.1 \mathrm{mg} / 0.1 \mathrm{ml}$ TA agree with others injecting higher doses $(25 \mathrm{mg} / 0.1 \mathrm{ml} \mathrm{TA}$ ) (Augustin and Schmidt-Erfurth 2006a; Augustin and Schmidt-Erfurth 2006b; Nicolo et al 2006; Ruiz-Moreno et al 2006a; RuizMoreno et al 2006b). Augustin and Schmidt-Erfurth treated 184 eyes with AMD secondary to CNV by PDT and $25 \mathrm{mg}$ intravitreal TA 16 hours later, and followed them for more than 6 months (Augustin and Schmidt-Erfurth 2006b). VA improvement averaged 1.22 Snellen lines after an average 1.21 sessions of PDT. The response to the combined therapy was good and did not depend on the lesion composition or size. The same authors have reported the outcome of pure occult lesions in 41 eyes with the same combined therapy (Augustin and Schmidt-Erfurth 2006a). VA improved in average from 20/133 at baseline to 20/81 at two years after an average 1.8 PDT sessions. Nicolo et al reported 11 eyes from 10 patients with occult CNV treated by $25 \mathrm{mg}$ intravitreal TA followed by PDT one month later. VA improved from an average 20/160 to 20/80 at one year (Nicolo et al 2006).

Theoretical risks of intravitreal TA injections include endophthalmitis, high IOP, cataract progression, retinal tear, retinal detachment and floaters. A prolongation of choroidal hypofluorescence following PDT and intravitreal TA has been reported recently (Luttrull and Spink 2007). The frequency of complications associated with the use of high TA dose does not seem to be higher in the series reported (Augustin and Schmidt-Erfurth 2006a; Augustin and Schmidt-Erfurth 2006b; Nicolo et al 2006; Ruiz-Moreno et al 2006a; Ruiz-Moreno et al 2006b).

Spaide et al (Spaide et al 2003; Spaide et al 2005) and Rechtman et al (Rechtman et al 2004) have reported increased IOP in 29\%-38\% of eyes after $4 \mathrm{mg}$ TA. Augustin and Schmidt-Erfurth have reported high IOP $(>25 \mathrm{mmHg})$ in 22 to $25 \%$ of eyes after $25 \mathrm{mg}$ TA in two different clinical series (Augustin and Schmidt-Erfurth 2006a; Augustin and Schmidt-Erfurth 2006b).

Cataract progression has already been described by several authors. Gillies et al (2004) reported cataract surgery in $24 \%$ of eyes 25 months after $4 \mathrm{mg}$ TA injection. Augustin and Schmidt-Erfurth described cataract surgery in 49\% and $42 \%$ of eyes treated by high dose intravitreal TA injection, respectively (Augustin and Schmidt-Erfurth 2006a; Augustin and Schmidt-Erfurth 2006b).

No association between increased IOP and lens opacification was noticed in our series during the second year, though it has been described previously (Gillies et al 2004). 
We have encountered no cases of endophthalmitis, retinal tear or retinal detachment as previously reported (Spaide et al 2003; Spaide et al 2005; Augustin and Schmidt-Erfurth 2006a; Augustin and Schmidt-Erfurth 2006b; Nicolo et al 2006). However, these series are small, and the power to detect these potentially severe complications is low.

The interval between PDT and TA injection is under discussion. We performed TA injection after PDT in order to avoid opacification of the vitreous body by TA which might block laser irradiation, and the inhibition of free-radical formation (Dweik et al 1997) interfering with the mechanism of action of PDT (Weishaupt et al 1976). The five day interval between PDT and intravitreal TA was chosen in order to avoid the photosensitizing effect of verteporfin in the event that any problem such as retinal detachment or endophthalmitis might appear after the injection, and before reperfusion or new vessel growth might take place.

The advantages of combining high dose intravitreal TA to PDT are a substantial reduction in the number of PDT sessions and of intravitreal injections.

Increased IOP and cataracts are side effects to be considered. The advantage of using high doses of intravitreal TA is to achieve a longer permanence of the drug in the vitreous cavity instead of 3 months achieved with $4 \mathrm{mg}$ intravitreal $\mathrm{TA}$, reducing the need to repeat the injection (Tano et al 1980). However we may also expect a longer duration of the side effects, especially of increased IOP. According to our results we can not conclude that high dose $(20 \mathrm{mg})$ intravitreal TA is better than low dose ( $4 \mathrm{mg}$ ).

The good VA results achieved by antiangiogenic drugs and the low rate of adverse events have reduced the indications of PDT associated to intravitreous TA (Rosenfeld, Brown et al 2006). However, the use of intravitreous antiangiogenic drugs is limited by the need of repeated intraocular injections and the inherent risks of endophthalmitis associated with this procedure, since antiangiogenic drugs do not permanently close $\mathrm{CNV}$, and it is not known how early exudation may reappear after cessation of treatment.

The association of antiangiogenic drugs to PDT might be a solution to this problem. The combined treatment PDT and ranibizumab seems to be more effective than PDT alone (Heier et al 2006) and does not seem to increase adverse events compared with PDT alone in normal monkey eyes (Kim et al 2006). The association of PDT with intravitreal ranibizumab has been reported in the FOCUS and the PROTECT clinical trials (Rosenfeld, Rich et al 2006). The preliminary results of these trials suggest that even though this association is safe and may reduce the number on ranibizumab injections required to achieve the inactivation of CNV, it may also reduce the benefits of ranibizumab. A retrospective study on 24 eyes treated by PDT and intravitreous bevacizumab demonstrated 2.04 Snellen lines mean improvement in VA (Dhalla et al 2006). Fifteen eyes (63\%) required only a single combined treatment for CNV resolution and the combined therapy was followed by no complications, including endophthalmitis, uveitis, and ocular hypertension. The association of PDT and intravitreal bevacizumab may also be useful in treating neovascular AMD by reducing retreatment rates and improving visual acuity. However, CNV is influenced by several mediators, many of them inflammatory, and not only by VEGF (Kijlstra et al 2005; Tatar et al 2006). Intravitreous TA may help blocking these inflammatory factors with a long standing effect due to its depot effect. We consider that TA associated with anti VEGF drugs and PDT may still have a role in the treatment of CNV secondary to AMD.

\section{References}

[Anon] 1999. Photodynamic therapy of subfoveal choroidal neovascularization in age-related macular degeneration with verteporfin: one-year results of 2 randomized clinical trials - TAP report. Treatment of agerelated macular degeneration with photodynamic therapy (TAP) Study Group. Arch Ophthalmol, 117:1329-45.

Augustin AJ, Schmidt-Erfurth U. 2006a. Verteporfin and intravitreal triamcinolone acetonide combination therapy for occult choroidal neovascularization in age-related macular degeneration. Am J Ophthalmol, 141:638-45.

Augustin AJ, Schmidt-Erfurth U. 2006b. Verteporfin therapy combined with intravitreal triamcinolone in all types of choroidal neovascularization due to age-related macular degeneration. Ophthalmology, 113:14-22.

Avery RL, Pieramici DJ, Rabena MD, et al. 2006. Intravitreal bevacizumab (Avastin) for neovascular age-related macular degeneration. Ophthalmology, 113:363-72 e5.

Blumenkranz MS, Bressler NM, Bressler SB, et al. 2002. Treatment of Age-Related Macular Degeneration with Photodynamic Therapy Study Group. Verteporfin Therapy for subfoveal choroidal neovascularization in age-related macular degeneration: three-year results of an open-label extension of 2 randomized clinical trials - TAP Report no. 5. Arch Ophthalmol, 120:1307-14.

Bressler NM. 2001. Photodynamic therapy of subfoveal choroidal neovascularization in age-related macular degeneration with verteporfin: two-year results of 2 randomized clinical trials-tap report 2. Arch Ophthalmol, 119:198-207.

Brown MM, Brown GC, Stein JD, et al. 2005. Age-related macular degeneration: economic burden and value-based medicine analysis. Can $J$ Ophthalmol, 40:277-87.

Chan WM, Lai TY, Wong AL, et al. 2006. Combined photodynamic therapy and intravitreal triamcinolone injection for the treatment of subfoveal choroidal neovascularisation in age related macular degeneration: a comparative study. Br J Ophthalmol, 90:337-41.

Chylack LT, Wolfe JK, Singer DM, et al. 1993. The Lens Opacities Classification System III. The Longitudinal Study of Cataract Study Group. Arch Ophthalmol, 111:831-6.

Dhalla MS, Shah GK, Blinder KJ, et al. 2006. Combined photodynamic therapy with verteporfin and intravitreal bevacizumab for choroidal neovascularization in age-related macular degeneration. Retina, 26:988-93. 
Dweik RA, Lewis M, Kavuru M, et al. 1997. Inhaled corticosteroids and beta-agonist inhibit oxidant production by bronchoalveolar lavage cells from normal volunteers in vivo. Immunopharmacology, 37:163-6.

Gillies MC, Simpson JM, Billson FA, et al. 2004. Safety of an intravitreal injection of triamcinolone: results from a randomized clinical trial. Arch Ophthalmol, 122:336-40.

Gragoudas ES, Adamis AP, Cunningham ET, et al. 2004. Pegaptanib for Neovascular Age-Related Macular Degeneration. for the VEGF Inhibition Study in Ocular Neovascularization Clinical Trial Group. NEngl $J$ Med, 351:2805-16.

Heier JS, Boyer DS, Ciulla TA, et al. 2006. Ranibizumab combined with verteporfin photodynamic therapy in neovascular age-related macular degeneration: year 1 results of the FOCUS Study. Arch Ophthalmol, 124:1532-42.

Jonas JB, Kreissig I, Hugger P, et al. 2003. Intravitreal triamcinolone acetonide for exudative age related macular degeneration. $\mathrm{Br} \mathrm{J} \mathrm{Oph-}$ thalmol, 87:462-8.

Kijlstra A, La Heij E, Hendrikse F. 2005. Immunological factors in the pathogenesis and treatment of age-related macular degeneration. Ocul Immunol Inflamm, 13:3-11.

Kim IK, Husain D, Michaud N, et al. 2006. Effect of intravitreal injection of ranibizumab in combination with verteporfin PDT on normal primate retina and choroid. Invest Ophthalmol Vis Sci, 47:357-63.

Luttrull JK, Spink CJ. 2007. Prolongation of choroidal hypofluorescence following combined verteporfin photodynamic therapy and intravitreal triamcinolone acetonide injection. Retina, 27:688-92.

Meads C, Hyde C. 2004. Photodynamic therapy with verteporfin is effective, but how big is its effect? Results of a systematic review. $\mathrm{Br} J$ Ophthalmol, 88:212-17.

Michels S, Schmidt-Erfurth U. 2003. Sequence of early vascular events after photodynamic therapy. Invest Ophthalmol Vis Sci, 44:2147-54.

Miller JW, Walsh AW, Kramer M, et al. 1995. Photodynamic therapy of experimental choroidal neovascularization using lipoprotein-delivered benzoporphyrin. Arch Ophthalmol, 113:810-18.

Nicolo M, Ghiglione D, Lai S, et al. 2006. Occult with no classic choroidal neovascularization secondary to age-related macular degeneration treated by intravitreal triamcinolone and photodynamic therapy with verteporfin. Retina, 26:58-64.

Peyman GA, Kazi AA, Unal M, et al. 2000. Problems with and pitfalls of photodynamic therapy. Ophthalmology, 107:29-35.

Rechtman E, Danis RP, Pratt LM, et al. 2004. Intravitreal triamcinolone with photodynamic therapy for subfoveal choroidal neovascularisation in age related macular degeneration. Br J Ophthalmol, 88:344-7.
Reinke MH, Cankis C, Husain D, et al. 1999. Verteporfin photodynamic therapy retreatment of normal retina and choroid in the cynomolgus monkey. Ophthalmology, 106:1915-23.

Rosenfeld PJ, Brown DM, Heier JS, et al. 2006. Ranibizumab for neovascular age-related macular degeneration. $N$ Engl J Med, 355:1419-31.

Rosenfeld PJ, Rich RM, Lalwani GA. 2006. Ranibizumab: Phase III clinical trial results. Ophthalmol Clin North Am, 19:361-72.

Ruiz-Moreno JM, Montero JA, Artola A, et al. 2005. Anterior chamber transit of triamcinolone after intravitreal injection. Arch Ophthalmol, 123:129-30.

Ruiz-Moreno JM, Montero JA, Barile S. 2006a. Triamcinolone and PDT to treat exudative age-related macular degeneration and submacular hemorrhage. Eur J Ophthalmol, 16:426-34.

Ruiz-Moreno JM, Montero JA, Barile S, et al. 2006b. Photodynamic therapy and high-dose intravitreal triamcinolone to treat exudative age-related macular degeneration: 1-year outcome. Retina, 26:602-12.

Ruiz-Moreno JM, Montero JA, Zarbin MA. 2007. Photodynamic therapy and high-dose intravitreal triamcinolone to treat exudative age-related macular degeneration: 2-year outcome. Retina, 27:458-61.

Schmidt-Erfurth UM, Elsner H, Terai N, et al. 2004. Effects of verteporfin therapy on central visual field function. Ophthalmology, 111:931-9.

Sharma S, Brown GC, Brown MM, et al. 2001. The cost-effectiveness of Photodynamic therapy for fellow eyes with subfoveal choroidal neovascularization secondary to age-related macular degeneration. Ophthalmology, 108:2051-9.

Spaide RF, Sorenson J, Maranan L. 2003. Combined photodynamic therapy with verteporfin and intravitreal triamcinolone acetonide for choroidal neovascularization. Ophthalmology, 110:1517-25.

Spaide RF, Sorenson J, Maranan L. 2005. Photodynamic therapy with verteporfin combined with intravitreal injection of triamcinolone acetonide for choroidal neovascularization. Ophthalmology, 112:301-4.

Tano Y, Chandler D, Machemer R. 1980. Treatment of intraocular proliferation with intravitreal injection of triamcinolone acetonide. Am J Ophthalmol, 90:810-16.

Tatar O, Adam A, Shinoda K, et al. 2006. Expression of VEGF and PEDF in choroidal neovascular membranes following verteporfin photodynamic therapy. Am J Ophthalmol, 142:95-104.

Wang YS, Friedrichs U, Eichler W, et al. 2002. Inhibitory effects of triamcinolone acetonide on bFGF-induced migration and tube formation in choroidal microvascular endothelial cells. Graefes Arch Clin Exp Ophthalmol, 240:42-8.

Weishaupt K, Gomer C, Dougherty T. 1976. Identification of singlet oxygen as the cytotoxic agent in photo-inactivation of murine tumor. Cancer Res, 36:2326-9. 
